\title{
Variations of erythemal ultraviolet irradiance and dose at Tartu/Tõravere, Estonia
}

\author{
K. Eerme*, U. Veismann, R. Koppel \\ Tartu Observatory, 61602 Tõravere, Tartumaa, Estonia
}

\begin{abstract}
The variations of erythemally weighted ultraviolet (UV) irradiance and its relationships with atmospheric characteristics during 3 annual cycles (1998-2000) at 1 site (Tõravere, Estonia; $58.3^{\circ} \mathrm{N}, 26.5^{\circ} \mathrm{E} ; 70 \mathrm{~m}$ above sea level) were studied, with the further aim to estimate the erythemal doses for past years. In clear sky conditions the daily erythemal dose and noon irradiance exhibit total-ozone-related asymmetry in the annual cycle, with $27 \%$ lower values at spring equinox than at autumnal equinox. The clear sky ratio of erythemally weighted to broadband (300 to $3000 \mathrm{~nm}$ ) irradiance increases from $(0.5 \pm 0.25) \times 10^{-4}$ to $(2 \pm 0.1) \times 10^{-4}$ with an increase in solar elevation from $10^{\circ}$ to $55^{\circ}$. In overcast low cloudiness conditions this ratio is higher. A simple empirical method to estimate the summer half-year erythemal dose for past years is proposed, and the doses were calculated for 1967-2000. A sharp drop in summer half-year sunshine duration and erythemal dose was found around 1975, with a following quasi-linear recovery to the values met in 1967-1975. A comparison with the measured and Total Ozone Mapping Spectrometer (TOMS)-derived data is provided for 1998-2000. In the fine summer of 1999 and the 'normal' one of 2000, the measured, estimated and TOMS-derived half-year doses agreed to within $0.7 \%$. In the extremely cloudy summer of 1998 , the difference between the measured and estimated values was $1.7 \%$ and between the measured and TOMS-derived values $6 \%$.
\end{abstract}

KEY WORDS: Erythemal ultraviolet radiation $\cdot$ UV dose $\cdot$ UV index $\cdot$ Atmospheric turbidity $\cdot$ Total ozone $\cdot$ Cloud factor $\cdot$ Relative sunshine duration

\section{INTRODUCTION}

The major characteristics of any climatic quantity are its long-term mean value, natural variance, probability of extremes and predictability. For detecting the anomalies and trends in the recorded UV dose and irradiance, a reference to the 'normal' background is necessary. The spectral response of many UV sensors matches the Commission Internationale de L'Éclairage (CIE) erythemal action spectra standard or DIN 5050 (McKinlay \& Diffey 1987). A long-term mean annual course of erythemal irradiance at any geographical site depends first and foremost on the solar-elevation annual cycle. The next most important factors, strongly dependent on the dominating weather regimes, are

*E-mail: kalju@aai.ee the mean seasonal cloudiness, the mean annual cycle of atmospheric total ozone, and the mean atmospheric turbidity cycle. Surface-albedo inhomogeneities, especially the variations of snow cover, also affect the UV radiation reaching the ground (Degünther \& Meerkötter 2000a, Weihs et al. 2001). Increased atmospheric turbidity, similarly to overcast cloudiness (Frederick \& Steele 1995), usually enhances the relative contribution of the UV irradiance (Lorente et al. 1994), especially on wavelengths of $320-330 \mathrm{~nm}$ (Mayer et al. 1998). Transmission in cloudy atmospheres relative to that in clear ones drops sharply at wavelengths below 310-320 nm (Erlick et al. 1998). The radiation through a cloudy sky can be either higher or lower than in the case of a clear sky (Weihs et al. 2000). The influence of clouds is difficult to quantify and is mostly described by different empirical UV/cloud models or sky formulae (Frederick \& Steele 1995, Schafer et al. 1996, Thiel 
et al. 1997, Josefsson \& Landelius 2000, Sabburg \& Wong 2000). The local UV radiation data records often cover time intervals too short to enable the construction of statistically confident climatic mean annual cycles or to find the trends or periodic changes. This difficulty to some extent is expected to be overcome by using statistical relationships between the UV radiation and major governing factors as the proxies.

In the present paper we study the climatologically important relationships between the erythemally weighted UV and the potential proxies, with the final aim of estimating the erythemally weighted UV doses for past years. Summer half-year doses are calculated for 1967-2000 using the relationships found.

\section{INSTRUMENTS AND DATA SETS}

The UV data were collected in 1998-2000 using the Scintec UV SET sensor (Eerme et al. 2000, Veismann et al. 2000) at the Tartu/Tõravere Baseline Surface Radiation Network (BSRN) station $\left(58.3^{\circ} \mathrm{N}, 26.5^{\circ} \mathrm{E} ; 70 \mathrm{~m}\right.$ above sea level). Simultaneous data from routine pyranometric and sunshine-duration measurements, using the Campbell-Stokes heliograph, as well as hourly cloud detection data were used.

The Scintec UV SET sensor has an erythemally weighted spectral response (CIE 1987, DIN 5050) and is thermostated to avoid temperature dependence. The spectral response was checked at the Tartu Observatory using a double monochromator SDL-1 produced by LOMO. The CIE-weighted response as well as the manufacturer's calibration was regularly checked using a standard FEL lamp calibrated by Oriel Instruments in spectral irradiance units traceable to NIST standards. An additional indirect check of the sensor response was made by statistical comparison with the TOMS-derived clear-weather erythemal doses. No systematic changes were found. Erythemal irradiance is measured in $\mathrm{W}_{\text {eff }} \mathrm{m}^{-2}$ and erythemal dose in $\mathrm{J}_{\text {eff }} \mathrm{m}^{-2}$ units, where the subscript 'eff' denotes the integrated product of the real spectral value and the erythemal response. Often the erythemal irradiance is characterized by UV index. The unit of the UV index scale is $25 \mathrm{~mW}_{\text {eff }} \mathrm{m}^{-2}$.

The ground-level daily erythemal dose, $H$, as well as the irradiance can be expressed as:

$$
H=H_{\text {clear }} K_{\text {ozone }} K_{\text {turbidity }} K_{\text {cloudiness }}
$$

where $H_{\text {clear }}$ denotes the clear-weather dose in conditions of long-term mean total ozone and atmospheric turbidity for the corresponding time, $K_{\text {ozone }}$ a coefficient accounting for the effect of the total ozone anomaly, $K_{\text {turbidity }}$ a coefficient accounting for the effect of turbidity anomaly and $K_{\text {cloudiness }}$ a cloudiness transmis- sion factor or cloud factor. The normal values and variations of total ozone during its yearly cycle in 1979-2000 were obtained using the available TOMS dataset (http://jwocky.gsfc.nasa.gov). As a result, the Estonian total ozone climatology was prepared (Eerme et al. 2002). During our regular measurements of the erythemal irradiance and its doses the total ozone values close to seasonal extremes were captured, and the range of variation of $K_{\text {ozone }}$ was estimated to be $1 \pm$ 0.15 . The range of variation in $K_{\text {turbidity }}$ is more uncertain, because of the lack of direct data on the turbidity characteristics in the UV spectral region. Guided by data on the relationship between broadband atmospheric transmittance and diffuse/global ratio (Põldmaa 1978), we found the lowest and mean turbidities to have been captured in our measurement cycle in several cases. The situations close to the highest turbidity were not observed. Quite a strong trend in the decrease in the integral atmospheric transmittance at our observational site was noted in 1955-1995; this was followed by an increase to the previous level (Russak et al. 1997) related to decreasing atmospheric pollution and reduced agriculture. The record highest atmospheric turbidities were found in the 2 years after the Mt. Pinatubo eruption. According to obtained, though still insufficient, data on $K_{\text {turbidity, }}$ the range of variation is $1 \pm 0.1 . K_{\text {cloudiness }}$ will be covered in Sections 4 and 5 .

\section{CLEAR-WEATHER CONDITIONS}

\subsection{Background clear-weather annual cycle}

The clear-weather daily erythemally weighted doses, $H$ (in $\mathrm{J}_{\text {eff }} \mathrm{m}^{-2}$ ), as well as the noon UV-index values from the 1998-2000 data were used for constructing the averaged background annual cycle presented in Fig. 1 for the doses. The cycle is asymmetric relative to the summer solstice. The reason for this asymmetry is obviously the asymmetry in the total ozone annual cycle (Eerme et al. 2002). The differences of the first and second half-year doses relative to the assumed symmetric mean are -6 and $+6 \%$. The median day appears $5 \mathrm{~d}$ after the summer solstice. Similar asymmetry in UV radiation has been observed in Japan at $35^{\circ} \mathrm{N}$ (Sasaki et al. 1993), as well as at erythemal irradiance measurement sites near $45^{\circ} \mathrm{S}$ in New Zealand (Ryan et al. 1996).

The data published on the atmospheric integral transmittance at Tõravere since 1955 indicate a decrease from January to August and a following increase (Russak et al. 1997). If the UV transmittance changes similarly, then it dampens rather than amplifies the asymmetry in UV-dose cycle. Around both equinoxes the mean transmittances are close to each other. 


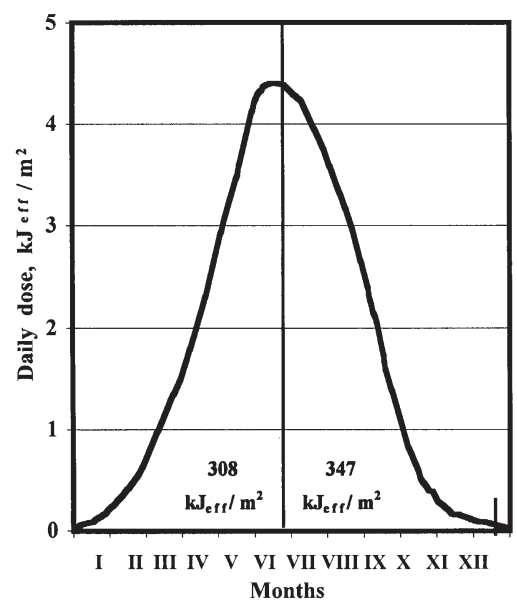

Fig. 1. Clear-weather annual cycle of erythemal doses in $\mathrm{kJ}_{\text {eff }}$ $\mathrm{m}^{-2}$ at the Tartu/Tõravere Baseline Surface Radiation Net work (BSRN) station $\left(58.3^{\circ} \mathrm{N}, 26.5^{\circ} \mathrm{E}\right)$

Table 1. Best-fitting UV index values at noon and the daily doses for equinox days

\begin{tabular}{|lccc|}
\hline Equinox & $\begin{array}{r}\text { No. of points } \\
\text { within } \pm 2 \mathrm{wk}\end{array}$ & $\begin{array}{c}\text { UV } \\
\text { index }\end{array}$ & $\begin{array}{c}\text { Dose } \\
\left(\mathrm{J}_{\mathrm{eff}} \mathrm{m}^{-2}\right)\end{array}$ \\
\hline $\begin{array}{l}\text { Spring } \\
\text { Autumn }\end{array}$ & 15 & $2.16 \pm 0.22$ & $1125 \pm 95$ \\
& 12 & $2.96 \pm 0.12$ & $1550 \pm 90$ \\
\hline
\end{tabular}

For detecting the ratios of the noon erythemal irradiances and the daily doses corresponding to the spring and autumn equinoxes, 15 and $12 \mathrm{~d}$ with the mean cloud amount less than $2 / 10$ were found within $2 \mathrm{wk}$ on either side of the spring and autumn equinoxes, respectively. The bestfitting UV index values at noon and the daily doses for equinox days are presented in Table 1. Both values were $27 \%$ lower at the spring equinox than those at the autumn equinox. Around the autumn equinox, UV index values between 2.5 and 4 are reached at solar elevations about $5^{\circ}$ lower than around the spring equinox.

\subsection{Noon UV index response to total ozone and turbidity}

During 1998-2000, 81 days were found when at least the noon hour was clear. For those days the noon values of the UV index were compared with the simultaneous broadband diffuseto-global-irradiance ratios characteriz- ing the atmospheric turbidity. Around the summer solstice, at noon, solar elevation, $h$, values between $52.5^{\circ}$ and $55.2^{\circ}$, the mean clear-weather noon UV index was $6.54 \pm 0.20$, and the mean broadband irradiance $839 \pm$ $16 \mathrm{~W} \mathrm{~m}^{-2}$. Several pairs of spring and autumn days with nearly equal noon solar elevation were found. Examples are presented in Table 2, where the values of solar elevation, total ozone, the diffuse-to-globalirraditation ratio and UV index are given. At nearly equal total ozone values, the UV index tends to be higher at higher turbidities due to more scattering.

At low atmospheric turbidity (a ratio of broadband diffuse to global irradiance of about $8 \%$ ), the probability density distribution of the noon UV index (from half an hour before the local noon to half an hour after) manifest an explicit narrow maximum (variations less than $1.5 \%$ ) near the highest values (Fig. 2a). The maximum broadens to a range of about $6 \%$ at the highest recorded midsummer noon turbidity, corresponding to a ratio of diffuse to global irradiance of $18 \%$ (Fig. 2b).

\subsection{Ratio of erythemally weighted to broadband irradiance}

The ratios of erythemally weighted irradiance (in $\mathrm{W}_{\text {eff }} \mathrm{m}^{-2}$ ) to the broadband irradiance (in $\mathrm{W} \mathrm{m}^{-2}$ ) were compared. In midwinter at noon solar elevations near $10^{\circ}$, this ratio was about $(5 \pm 2.5) \times 10^{-5}$ and increased to values of $(1.9-2.1) \times 10^{-4}$ during summer solstice. So the relative contribution of noon erythemal irradiance in clear-weather conditions can differ by up to 4 times in a year. Around the spring equinox it was close to $1 \times$

Table 2. Examples of pairs of spring and autumn days with nearly equal noon solar elevation. Values of total ozone, the diffuse-to-global-irradiation ratio and UV index are given for pairings in which the values of total ozone are different and those for which total ozone was the same but turbidity different. DU: Dobson units

\begin{tabular}{|lcccc|}
\hline $\begin{array}{l}\text { Date } \\
(\mathrm{d} / \mathrm{mo} / \mathrm{yr})\end{array}$ & $\begin{array}{c}\text { Solar elevation } \\
\text { (degrees) }\end{array}$ & $\begin{array}{c}\text { Total ozone } \\
\text { (DU) }\end{array}$ & $\begin{array}{c}\text { Diffuse-to-global } \\
\text { ratio }(\%)\end{array}$ & $\begin{array}{c}\text { UV } \\
\text { index }\end{array}$ \\
\hline $\begin{array}{l}\text { Different ozone } \\
29 / 03 / 2000\end{array}$ & & & & \\
$13 / 09 / 1998$ & 35.3 & 394 & 14.4 & 2.51 \\
04/04/1999 & 35.5 & 279 & 11.8 & 3.60 \\
08/09/1999 & 37.4 & 360 & 12.5 & 2.87 \\
$17 / 05 / 1999$ & 37.4 & 288 & 15.2 & 3.58 \\
$17 / 05 / 1998$ & 51.1 & 423 & 15.2 & 4.36 \\
Equal ozone, different turbidity & 348 & 15.1 & 5.60 \\
$13 / 06 / 1999$ & 54.9 & 312 & & \\
$10 / 06 / 2000$ & 54.8 & 312 & 8.0 & 6.66 \\
$19 / 06 / 1999$ & 55.1 & 341 & 12.1 & 6.30 \\
$28 / 06 / 1999$ & 55.0 & 336 & 16.9 & 6.32 \\
$14 / 06 / 1999$ & 55.0 & 321 & 16.8 & 6.73 \\
$15 / 06 / 1999$ & 55.0 & 327 & 14.5 & 6.56 \\
\hline
\end{tabular}



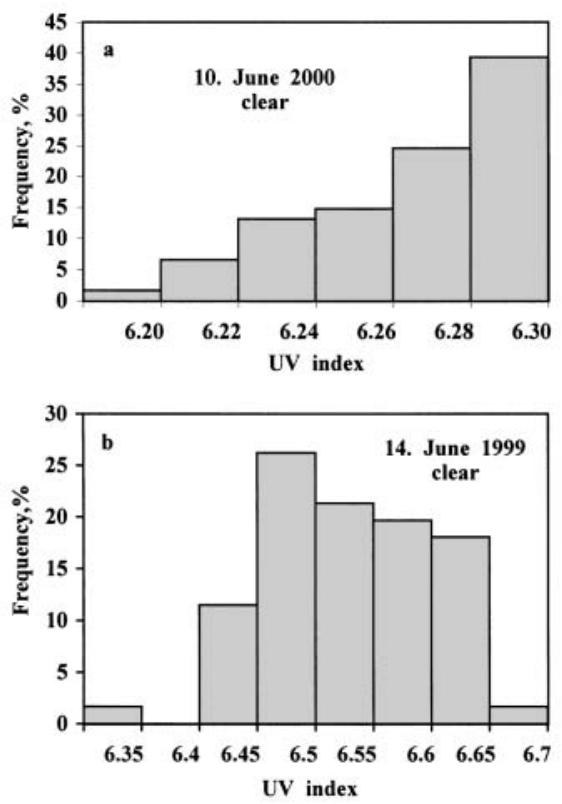

Fig. 2. Clear-weather probability density distributions of UV index during the hour around noon. (a) Low turbidity, diffuse irradiance of $8 \%$; (b) high turbidity, diffuse irradiance of $18 \%$

$10^{-4}$, and around the autumn equinox $1.3 \times 10^{-4}$. The lowest values of $(0.8-1.0) \times 10^{-4}$ were recorded during the spring equinox of 1999 in the presence of high total ozone (between 470 and 390 Dobson units [DU]).

The amplitude of variation of the noon value of the UV index during a year is approximately 4 times higher than that of the noon broadband irradiance. The clear-sky values were found in the noon solar elevation range from $10^{\circ}$ to $55^{\circ}$. Across this range the broadband irradiance values differ by about 6 times (from 140 to $860 \mathrm{~W} \mathrm{~m}^{-2}$ ) and the UV index values by nearly 24 times (from 0.29 to 6.85 ). Stronger scattering in the UV region leads to the larger differences.

\section{PARTIAL CLOUDINESS}

\subsection{Cloudiness transmittance factor}

There are 3 quantities in the traditional meteorological databases that it is possible to relate to UV irradiance and dose. The cloud amount and type are detected every $3 \mathrm{~h}$ or in better cases every hour. The total, direct and diffuse broadband irradiance data are regularly recorded in many meteorological stations using pyranometers. At many sites the duration of bright sunshine is recorded. Despite the fact that at Tartu/Tõravere the direct-beam contribution reaches about $50 \%$ of the recorded erythemal irradiance only around the midsummer noon, the daily doses depend significantly on how much the sun is obscured.
In summer the simultaneous appearance of different cloud types is usual. In most cases the cloud transmittance effect (cloud factor) on the UV irradiance or dose is determined as the ratio between the value in specified cloud conditions and the assumed corresponding value under a clear sky. We denoted this cloud transmittance factor or cloud factor by $K_{\text {cloudiness }}$ in Section 2 . The parametrization of cloud characteristics in statistical relationship describing the attenuation of UV irradiance has been presented using different sky formulae. The cloud-cover fraction measured in tenths in the second-degree expression was used by Bais et al. (1993) and in the third-degree expression by Schafer et al. (1996). Thiel et al. (1997) produced the sky formula:

$$
1-\Sigma a b^{3}
$$

where $a$ is the attenuation coefficient for each cloud type and $b$ the fraction of whole sky cloud ( 0 to 1 ). It was found (Thiel et al. 1997) that for cloud cover in the range below 4 octas the attenuation is independent on cloud type. It was also shown (Josefsson \& Landelius 2000) that the cloud effect in the UV region is less than over the whole solar spectrum, and the solar-elevation dependency in the effect of clouds is small. The cloud data do not include direct information regarding whether the sun is obscured or not, and the hourly samples of cloud cover often give a distorted picture for a whole day.

Here a correlation between the daily erythemal dose (relative to the assumed corresponding clear day) and the cloudiness-related characteristics (the daily relative sunshine duration, the daily mean low cloud amount and the daily mean cloud amount at 2 upper levels) was studied using the data from 1998-1999. The amount of high, middle and low clouds in tenths has been routinely recorded every day at half past every hour at the present Tartu/Tõravere BSRN station since 1955. Daily sunshine duration values have been recorded using the Campbell-Stokes heliograph (burning method) since 1967. Partial correlation of the daily erythemal dose with both cloud amounts was found to be statistically insignificant, and the regression was almost determined by the mean relative sunshine duration, $S$, during a day. $S$ was found by dividing the recorded sunshine duration by the length of day. It should be mentioned that in early morning and late evening the heliograph does not react to direct irradiance below the threshold. On days with good transparency its value does not exceed 0.95 and on hazy days it is as low as 0.85 . The days with $S$ between 0.1 and 0.85 were included in the group of partly cloudy days, representing between 62 and $75 \%$ of all summer half-year days in 1967-2000. The days with less sunshine were classified as overcast days, and the days with more relative sunshine as clear days. The maxi- 


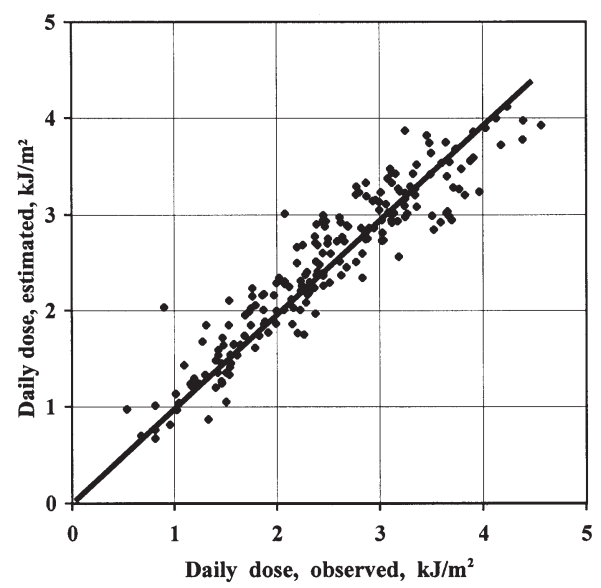

Fig. 3. Comparison of observed and regression-computed daily erythemal doses for 1998-1999

mum difference in daily dose from the presence of $1 / 10$ to $3 / 10$ of clouds does not exceed a few percent as compared to the clear-sky conditions. For the estimation of the influence of partial cloudiness, $K_{\text {cloudiness }}$ during the summer half-year the following linear regression formula is proposed:

$$
K_{\text {cloudiness }}=0.581 S+0.432
$$

The standard deviations of the coefficient values of Eq. (3) on the $95 \%$ significance level are 0.065 and 0.036 , respectively. The data of 262 days in the years 1998 and 1999 were used to contribute to the regression. In 2000 the instrument was installed in another place with a slightly less open horizon; therefore these data were not included. A comparison of computed and observed daily doses in $\mathrm{J}_{\text {eff }}$ on partly cloudy days between spring and autumnal equinoxes in 1998 and 1999 is presented in Fig. 3. The total dose of this period provides 85 to $92 \%$ of the yearly value.

\subsection{Cirrus and cumulus clouds}

The hourly data of visual cloud observations on days with only upper-level clouds were used to study the influence of cirrus clouds on erythemal irradiance. Those full days were found to occur more frequently in spring (12 in March, 10 in April and 8 in May) and autumn (10 in September and 7 in October) and rarely in midsummer (1 each in June, July and August, all in 1999). During 3 winters only 2 cases occurred from December to January. The number of days having only part-time upper-level cloudiness is larger.

The noon-hour values of the UV index in the presence of cirrus clouds only are mostly close to those under a clear sky at similar solar elevations. For cloud amounts less than $5 / 10$ and a non-obscured sun, the dif- ferences in the UV index values and in the total irradiance are small. More clouds tend to increase the ratio of erythemally weighted irradiance to the broadband irradiance because cloudy skies provide less attenuation of UV light. In Fig. 4, 2 probability density distributions of the noon UV index values corresponding to 5 (11 May 1998) and 8 (6 June 1998) tenths of cirrus clouds are presented. The increasing cloud amount and opacity causes more attenuation of direct irradiance and shifts the maximum of the probability density distribution towards lower values. With medium cloud amounts, a bimodal distribution (Fig. 4b) develops, containing a mode corresponding to non-attenuated direct irradiance and another one corresponding to an obscured sun. In the latter case the values are 50 to $90 \%$ of those of the non-attenuated mode. The distribution characteristics are not directly related to the cloud amount.

Convective cumulus clouds present another typical fine-weather cloudiness situation, with the highest frequency at noon and slightly after in summer. Individual vertically developed clouds influence the groundlevel UV irradiance by their albedo, scattering and extinction effects. As a result, the UV irradiance can be enhanced or reduced depending on the cloud structure (Degünther \& Meerkötter 2000b, Sabburg \& Wong 2000). Weihs et al. (2000) found that the largest ratios of cloud radiance to the clear-sky reference radiance in UV were 2.5 .

The probability density distributions of the noonhour UV irradiance manifest the effect of cumulus
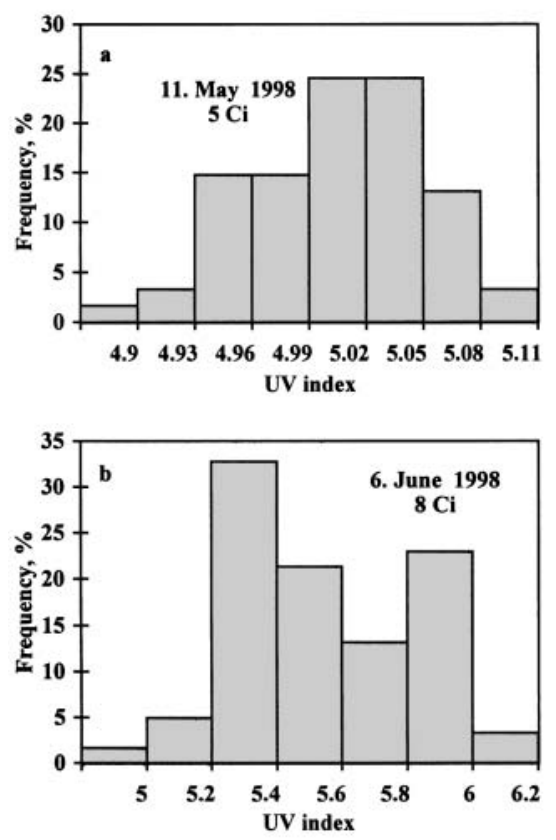

Fig. 4. Probability density distributions of the UV index during the noon hour in the presence of cirrus clouds only. (a) $\frac{5}{10}$ i (b) $8 / 10$ 

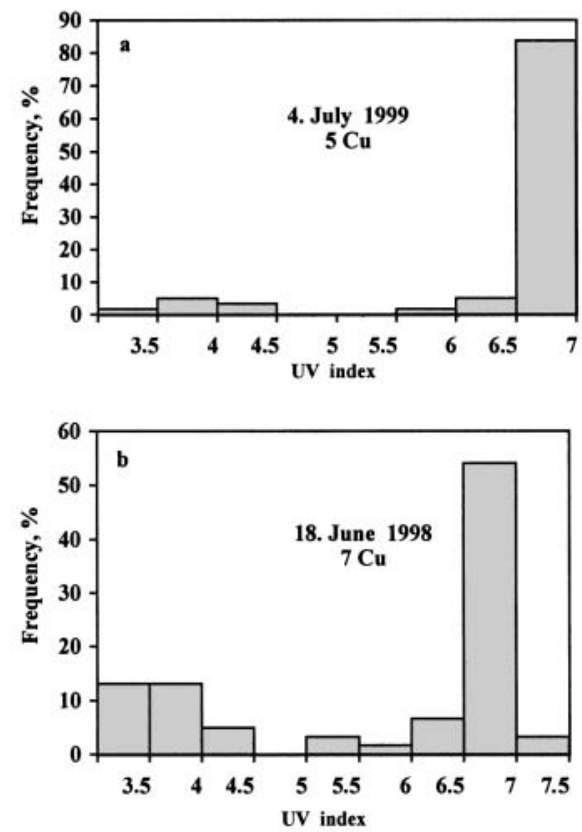

Fig. 5. Probability density distributions of UV index during the noon hour in the presence of cumulus clouds only. (a) $5 / 10$; (b) $7 / 10$

clouds through bimodality. The major modes correspond to a obscured and non-obscured sun. Around summer solstice the mean erythemal irradiance values of an obscured sun are 50 to $55 \%$ of those during the non-obscured-sun episodes. The probability of values between the major modes corresponds to the partial attenuation of the sun and is low except for the cases of poor vertical development of partly semitransparent clouds. Examples of probability density distributions corresponding to different cumulus cloud amounts are presented in Fig. 5. If cumulus and cirrus clouds are present simultaneously, the background of the bimodal distribution is enhanced.

\section{OVERCAST SKIES}

\subsection{Overcast daily doses}

The differences in mean transmittance $K_{\text {cloudiness }}$ of major overcast cloudiness types reach about 4 times at similar solar elevation. For stratus clouds a mean relationship for dose was found:

$$
H_{\text {overcast }}=0.27 H_{\text {clear }}
$$

In the cases of nimbostratus or fractonimbus clouds the mean value of the coefficient $K_{\text {cloudiness }}=0.27$ is approximately halved and in the cases of stratocumulus or middle-level clouds doubled. In a few cases conditions in which it is overcast with cirrus clouds occurred. These were included in the doubled-coefficient group. In days when the dominating cloud type changed during the day the relative contributions of each type were accounted for by considering their relative durations in calculating the value of $K_{\text {cloudiness. }}$. The coefficients $K_{\text {ozone }}$ and $K_{\text {turbidity }}$ were not taken into account for overcast days.

\subsection{Ratio of erythemal to broadband irradiance}

The ratio of erythemal to total broadband irradiance for overcast skies is usually higher than in clearweather conditions because the UV part above 310 to $320 \mathrm{~nm}$ is less attenuated (Frederick \& Steele 1995, Erlick et al. 1998). As compared to the clear-sky conditions, the ratio of erythemal to broadband irradiance was $75 \pm 10 \%$ higher at a solar elevation of $10^{\circ}, 20 \pm$ $5 \%$ higher at the equinox noon and $15 \pm 5 \%$ higher at the summer-solstice-noon solar elevation of about $55^{\circ}$. At solar elevations below $11.5^{\circ}$ the mean value of the erythemal/broadband ratio before solstice (after November 22) was $10 \pm 4 \%$ higher than that after solstice (before January 20). Due to the relatively high contribution from optically thick clouds, the midsummer mean noon UV index in overcast conditions was $30 \pm 11 \%$ (with extremes of 10 and $44 \%$ ) of that under a clear sky. The corresponding broadband irradiance was $24 \pm 11 \%$ (with extremes 7.6 and $47 \%$ ) of the mean under a clear sky. The noon-hour probability density distributions of overcast sky UV index values were skewed in most cases. Both the positive and negative skewness values occurred approximately to equal extent, depending on the optical depth structure of the cloud cover.

\section{ESTIMATION OF SUMMER HALF-YEAR ERYTHEMAL DOSE}

\subsection{Procedure}

The few published estimations of UV doses for past years are based on radiative-transfer calculations or on statistical relationships between UV radiation and different proxies (Fioletov et al. 2001, and references therein). The sunshine duration as a possible proxy is discussed by Josefsson \& Landelius (2000) but still is not used for long-term estimation of the UV doses. The estimation of the summer half-year erythemal dose here was performed for 186 days in the interval March 21 to September 22. The days were divided into 3 groups on the basis of relative sunshine duration, $S$. As mentioned above, these groups were: (1) clear days $(S>0.85)$, (2) partly cloudy days $(0.1<S<0.85)$, and 


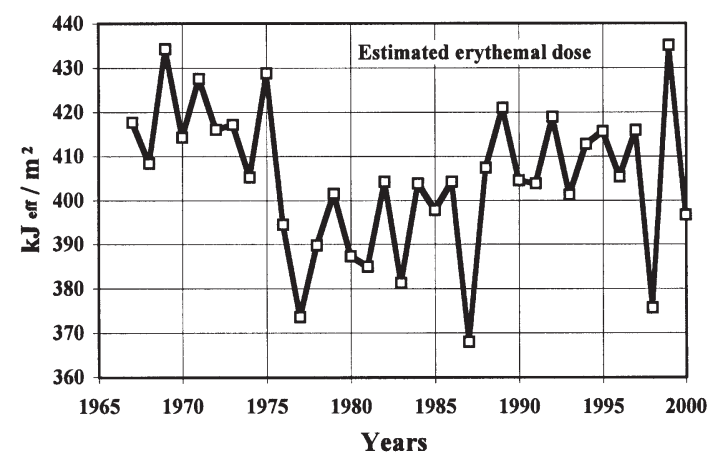

Fig. 6. Estimated summer half-year erythemal doses for $1967-2000$

(3) overcast days $(S<0.1)$. In a few cases the cloudiness and sunshine data were contradictive. On a totally cloudy day $S$ was above zero or vice versa. In all cases the sunshine data were used.

The clear-weather daily doses were found directly from the table of averaged clear-weather doses and corrected for the total ozone difference from the longterm average value for that day by $2 \%$ to 10 DU. No data on total ozone were available before 1973; thus no correction was made. For 1973-1978 the monthly mean values interpolated between the Riga and St. Petersburg stations were available. For most of these years the spring total ozone was about 20 DU higher than in the TOMS period since 1979.

The dose, $H$, in partial-cloudiness conditions was estimated using the regression with relative sunshine duration, $S$. Corrections for total ozone and atmospheric turbidity were not included.

The dose in overcast conditions was found by calculating the daily weighted attenuation factor considering the relative contribution of different cloud types characterized by 3 fixed attenuation values: $0.13,0.27$ and 0.54 .

\subsection{Results}

The estimation of the summer half-year erythemal dose here was performed for 34 years (1967-2000), including the years covered with measurements, 19982000. The estimated half-year doses in $\mathrm{J}_{\text {eff }} \mathrm{m}^{-2}$ are presented in Fig. 6. The probability density distributions of estimated-to-measured daily dose ratios for 1998-2000 are presented in Fig. 7. All the distributions are sharper than a normal distribution. The median values were between 0.992 and 1.014. A comparison of the estimated/measured ratios and the TOMSderived/measured ratios is presented in Table 3 . At continental sites in the midlatitudes of the Northern Hemisphere, the satellite-derived UV estimations were often found to be higher than the ground-level measured values (McKenzie et al. 2001). At Tartu/Tõravere
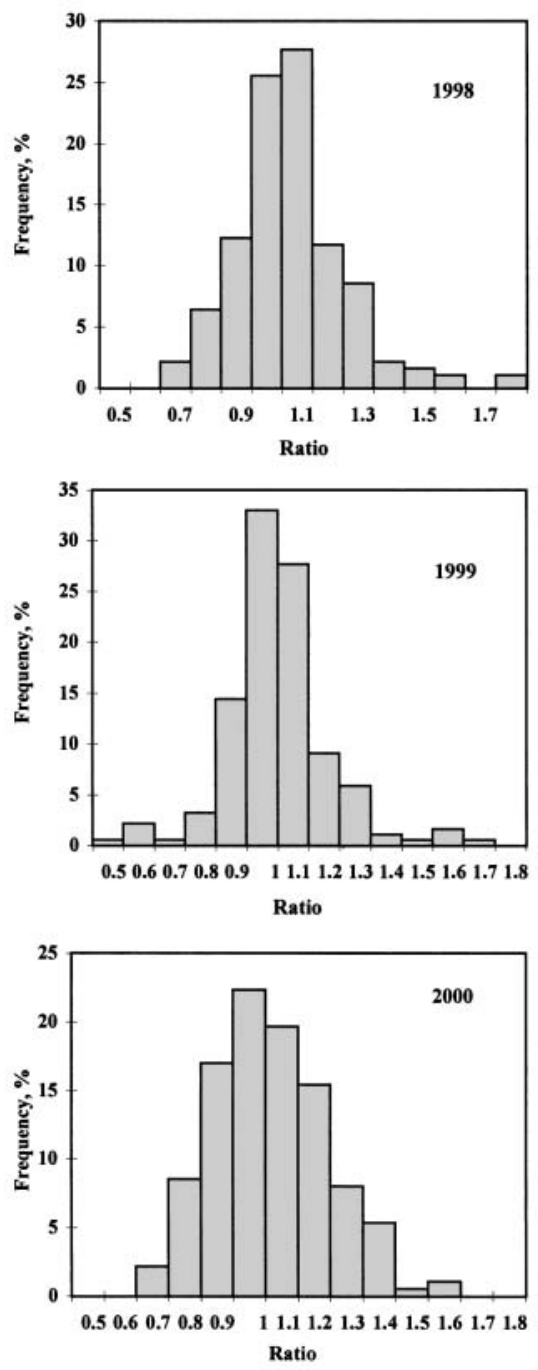

Fig. 7. Probability density distributions of the ratios estimated/measured daily erythemal dose for 1998-2000

Table 3. Comparison of the relative contribution of values $< \pm 20$ and $> \pm 40 \%$ in the ratios of daily erythemal dose and of the half-year dose ratios

\begin{tabular}{|lccc|}
\hline & 1998 & 1999 & 2000 \\
\hline $\begin{array}{l}\text { Daily ratios } \\
\text { Estimated/measured }\end{array}$ & & & \\
$\quad< \pm 20 \%$ & 0.77 & 0.83 & 0.74 \\
$> \pm 40 \%$ & 0.04 & 0.07 & 0.03 \\
TOMS-derived/measured & & & \\
$< \pm 20 \%$ & 0.73 & 0.76 & 0.82 \\
$> \pm 40 \%$ & 0.09 & 0.08 & 0.06 \\
Half-year dose & & & \\
Estimated/measured & 0.983 & 1.007 & 1.005 \\
TOMS-derived/measured & 0.940 & 0.995 & 1.005 \\
\hline
\end{tabular}


such a difference was not established. The local decline in industry and agriculture has reduced the absorbing aerosol amount in the atmosphere to the level typical of clean sites.

Looking at Fig. 6 one can notice 3 periods of distinguishable mean levels: 1967-1975, 1976-1987 and after 1987. The period 1967-1975 manifests the highest and 1976-1987 the lowest dose level, with a difference of $6.5 \%$. Taking into account only the values since 1976 , a trend of increase of about $2.4 \%$ decade $^{-1}$ can be found. It is similar but lower than the trend of $6.1 \pm$ $2.9 \%$ decade $^{-1}$ found by Borkowski (2000) in Robertson-Berger meter and Brewer spectrometer homogenized UV-B time series at Belsk in the period 1976-1997. At Tartu/Tõravere the sunshine duration for the time interval 21 March to 22 September has increased by about $8.5 \%$ (100 h) decade ${ }^{-1}$ since 1976 , and it is close to returning to the 1967-1975 level. An abrupt jump of $15 \%$ from 1410 sunshine hours (mean in 1967-1975) to 1200 sunshine hours in 1976-1987 was recorded. In the summer months (May-August) contributing about $70 \%$ of the yearly erythemal dose (Veismann et al. 2000), the correlation between the monthly mean low cloud amount and the East-Atlantic (EA) Jet index describing the Scandinavian-Mediterranean pressure difference anomaly in 1955-2000 was 0.54. It is believed that interdecadal variability of the North Atlantic thermohaline circulation is an important factor governing the weather patterns downwind over Northern Europe. In the 20th century the thermohaline circulation was the weakest around 1970, and after that it strengthened to a maximum in the late 1990s (Eden \& Jung 2001). The data on Estonian yearly mean precipitation, river runoff and water level in lakes manifest a minimum in 1965-1975 and a following increase (Jaagus et al. 1998). The decrease in sunshine duration is related to the strengthening of zonal circulation.

\section{SUMMARY AND CONCLUSIONS}

The major characteristics of climatic quantities including the erythemal UV irradiance and dose depend strongly on geographical site and can be determined by performing special studies. The annual cycles of the assumed clear-sky erythemal daily dose and the noon UV index values at Tartu/Tõravere manifest considerable asymmetry relative to the summer solstice, with both values at spring equinox being $27 \%$ lower than those at the autumn equinox. The deficit of the erythemal dose during the spring half-year and the surplus during the autumn half-year are $6 \%$. The median day occurs $5 \mathrm{~d}$ after the summer solstice.

In clear-weather conditions, in the range of solarelevation angle from $10^{\circ}$ to $55^{\circ}$ (maximum at Tõravere/-
Tartu latitude) the range of variation of broadband irradiance is approximately 6 times and that of erythemal irradiance 24 times. The ratio of erythemal-tobroadband irradiance ranges during a year from $(0.5 \pm$ $0.25) \times 10^{-4}$ to $(2.0 \pm 0.1) \times 10^{-4}$, displaying the highest value at noon around the summer solstice. In overcast conditions the ratio exhibits values higher than those under a clear sky at all solar-elevation angles (here between $10^{\circ}$ and $55^{\circ}$ ). The higher differences are found at smaller solar elevations ( $75 \%$ at $10^{\circ}$ ).

The noon-hour (from half an hour before to half an hour after the local solar noon) probability density distributions of erythemal irradiance in clear weather are positively skewed, with a sharp maximum at higher values. At the lowest atmospheric turbidities the maximum is about 4 times narrower than at mean turbidities. Extremely high turbidities were not found in 1998-2000. Cirrus clouds manifest similar effects as high turbidity. With increasing cloud amount, a mode corresponding to a obscured and semi-obscured sun (50 to $90 \%$ clear) strengthens. The mode corresponding to a non-obscured sun in noon-hour bimodal probability density distribution of the erythemal irradiance in cumulus cloudiness tends to occur at higher values than the clear-weather maximum. In midsummer the irradiance mode corresponding to a obscured sun is 50 to $55 \%$ of that in the non-obscured case. The contribution of this mode prevails above $7 / 10$ cloudiness.

In most cases the summer partial cloudiness consists of several different cloud types. The relative sunshine duration (the sunshine duration divided by the length of day) is the major factor governing daily erythemal dose. A linear regression formula is presented for estimation of the daily dose in these conditions. The mean attenuation factors of erythemal dose for the most widespread types of overcast cloudiness were found (values between 0.13 and 0.54), and their daily weighted combinations used to estimate the dose on overcast days.

Estimation of UV doses for past years from groundbased ancillary data has occurred in recent years due to the lack of time series of direct measurements long enough for climatological studies. The estimations are based on the radiative-transfer calculations or on empirical relationships using the data on global solar radiation, total ozone and snow cover. The duration of sunshine is mentioned as a possible proxy but still was not used for long-term estimations. Our estimation of the summer half-year erythemal UV dose for past years was performed using the regression with daily relative sunshine duration for partly cloudy days, the weighted cloud-attenuation factors for overcast days and the annual cycle of the assumed clear-sky erythemal dose. The results are presented for the period 1967-2000. The aim was not to obtain an excellent agreement 
between the estimated and measured erythemal dose values for every single day but for longer intervals. The measured daily erythemal doses of the summer halfyear were compared to the available TOMS-estimated doses and to those estimated by us. No systematic difference between the ground-level-measured and TOMS-derived daily dose was found in 1998-2000. The majority of the daily values (74 to $84 \%$ in different years) of the estimated/measured dose ratio falls into the range $\pm 20 \%$ and only a few values ( 2 to $6 \%$ ) exceed $\pm 40 \%$. Quite a similar amount (73 to $82 \%$ ) of TOMSderived/measured ratios in the range $\pm 20 \%$ and slightly more (6 to $9 \%$ ) values exceeding limits of $\pm 40 \%$ were found. On days with more than $6 / 10$ of optically thick low clouds the measured/TOMS-derived dose ratios can differ up to 2 times.

An abrupt drop was found in the estimated halfyear erythemal doses $(7.5 \%)$ as well as in the recorded half-year sunshine duration $(15 \%)$ between 1975 and 1977. Since 1976 an increasing cloudinessrelated linear trend of $2.4 \%$ decade $^{-1}$ in the summer half-year erythemal dose and $7.5 \%$ decade $^{-1}$ in the summer half-year sunshine duration can be found. The present levels of both quantities are close to the ones in 1967-1975. The period of high erythemal dose levels coincides with the weakest in 20th century North Atlantic thermohaline circulation as well as with the weakest zonal circulation over Estonia.

Acknowledgements. This study was supported by research grant no. 3609 of the Estonian Science Foundation. Appreciation is expressed to the Tartu/Torravere meteorological station of the Estonian Meteorological and Hydrological Institute for the availability of the pyranometric radiation, sunshine duration and cloudiness data. The authors would like to thank the anonymous reviewers for their useful suggestions on the original manuscript.

\section{LITERATURE CITED}

Bais AF, Zerefos CS, Meleti C, Ziomas IC, Tourpali K (1993) Spectral measurements of solar UV-B radiation and its relations to total ozone, $\mathrm{SO}_{2}$, and clouds. J Geophys Res 98(D3):5199-5204

Borkowski JL (2000) Homogenization of the Belsk UV-B series (1976-1997) and trend analysis. J Geophys Res 105(D4):4873-4878

Degünther M, Meerkötter R (2000a) Influence of inhomogeneous surface albedo on UV irradiance: effect of a stratus cloud. J Geophys Res 105(D18):22755-22761

Degünther M, Meerkötter R (2000b) Effect of remote clouds on surface UV irradiance. Ann Geophys 18:679-686

Eden C, Jung T (2001) North Atlantic interdecadal variability: oceanic response to the North Atlantic Oscillation (1865-1997). J Clim 14:676-691

Eerme K, Veismann U, Koppel R (2000) Ultraviolet irradiance in meteorologically contrasting summers of 1998 and 1999 in Estonia. Proc Estonian Acad Sci Phys Math 49:251-265

Eerme K, Veismann U, Koppel R (2002) Estonian total ozone climatology. Ann Geophys 20:247-255
Erlick C, Frederick JE, Saxena VK, Wenny BN (1998) Atmospheric transmission in the ultraviolet and visible: aerosols in cloudy atmospheres. J Geophys Res 103(D24): 31541-31556

Fioletov VE, McArthur LJB, Kerr JB, Wardle DI (2001) Longterm variations of UV-B irradiance over Canada estimated from Brewer observations and derived from ozone and pyranometer measurements. J Geophys Res 106(D24): 23009-23027

Frederick JF, Steele HD (1995) The transmission of sunlight through cloudy skies: an analysis based on standard meteorological information. J Appl Meteorol 34:2755-2761

Jaagus J, Järvet A, Roosaare J (1998). Modelling the climate change impact on river runoff in Estonia. In: Kallaste $\mathrm{T}$, Kuldna P (eds) Climate change studies in Estonia. Stockholm Environmental Institute, Tallinn, p 117-126

Josefsson W, Landelius T (2000) Effect of clouds on UV irradiance: as estimated from cloud amount, cloud type, precipitation, global radiation and sunshine duration. J Geophys Res 105(D4):4927-4935

Lorente J, Redaòo A, De Cabo X (1994) Influence of urban aerosol on spectral solar irradiance. J Appl Meteorol 33: 406-415

Mayer B, Kylling A, Madronich S, Seckmeyer G (1998) Enhanced absorption of UV radiation due to multiple scattering in clouds: experimental evidence and theoretical explanation. J Geophys Res 31241-31254

McKenzie RL, Seckmeyer G, Bais A, Kerr JB, Madronich S (2001) Satellite retrievals of erythemal UV dose compared with ground-based measurements at northern and southern midlatitudes. J Geophys Res 106:24051-24062

McKinlay AF, Diffey BL (1987) A reference action spectrum for ultraviolet induced erythema in human skin. CIE J 6: $17-22$

Põldmaa VK (1978) The ratio of direct to diffuse radiation on the Earth's surface. In: Ross J, Riives L (eds) Variability of cloudiness and radiation field. Institute of Astrophysics and Atmospheric Physics, Tartu, p 50-61

Russak V, Jõeveer A, Kallis A (1997) Atmospheric transmittance and its long-term changes in Estonia. Meteorol Z 6: 137-141

Ryan KG, Smith GJ, Rhoades DA, Coppell RB (1996) Erythemal ultraviolet insolation in New Zealand at solar zenith angles of $30^{\circ}$ and $45^{\circ}$. Photochem Photobiol 63:628-632

Sabburg J, Wong J (2000) Evaluation of a sky/cloud formula for estimating UV-B irradiance under cloudy skies. J Geophys Res 105(D24):29685-29691

Sasaki M, Takeshita S, Sugiura M, Sudo N, Miyake Y, Furusawa Y, Sakata T (1993) Ground-based observation of biologically active solar ultraviolet-B irradiance at $35^{\circ}$ latitude in Japan. J Geomagn Geoelectr 45:473-485

Schafer JS, Saxena VK, Wenny BN, Barnard W, DeLuisi JJ (1996) Observed influence of clouds on ultraviolet-B radiation. Geophys Res Lett 23:2625-2628

Thiel S, Steiner K, Seidlitz HK (1997) Modification of global erythemally effective irradiance by clouds. Photochem Photobiol 65:969-973

Veismann U, Eerme K, Koppel R (2000) Solar erythemal ultraviolet radiation in Estonia in 1998. Proc Estonian Acad Sci Phys Math 49:122-132

Weihs P, Webb AR, Hutchinson SJ, Middleton G (2000) Measurements of the diffuse UV sky radiance during broken cloud conditions. J Geophys Res 105(D4):4937-4944

Weihs P, Lenoble J, Blumthaler M, Martin T and 12 others (2001) Modelling the effect of an inhomogeneous surface albedo on incident UV radiation in mountaineous terrain: determination of an effective albedo. Geophys Res Lett 28: $3111-3114$

Submitted: June 15, 2001; Accepted: July 15, 2002

Proofs received from author(s): October 8, 2002 